\title{
Transatlantica
}

Revue d'études américaines. American Studies Journal

Sarah Orne Jewett. Le Pays des sapins pointus.

Edition de Cécile Roudeau (traduction, annotation et postface).Paris :

Editions Rue d'Ulm, 2004. 366 p. 23 euros.

\section{François Specq}

\section{Q OpenEdition}

1 Journals

\section{Édition électronique}

URL : http://journals.openedition.org/transatlantica/841

DOI : 10.4000/transatlantica.841

ISSN : 1765-2766

Éditeur

AFEA

\section{Référence électronique}

François Specq, «Sarah Orne Jewett. Le Pays des sapins pointus. », Transatlantica [En ligne], 1 | 2005, mis en ligne le 22 avril 2006, consulté le 29 avril 2021. URL : http://journals.openedition.org/ transatlantica/841; DOI : https://doi.org/10.4000/transatlantica.841

Ce document a été généré automatiquement le 29 avril 2021

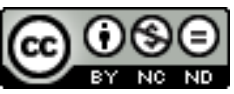

Transatlantica - Revue d'études américaines est mis à disposition selon les termes de la licence Creative Commons Attribution - Pas d'Utilisation Commerciale - Pas de Modification 4.0 International. 


\section{Sarah Orne Jewett. Le Pays des sapins pointus.}

Edition de Cécile Roudeau (traduction, annotation et postface).Paris : Editions Rue d'Ulm, 2004. 366 p. 23 euros.

\section{François Specq}

1 Il aura fallu plus d'un siècle pour que l'œuvre de Sarah Orne Jewett (1849-1909) commence enfin à parvenir au public français, révélant une étendue quelque peu oubliée du paysage littéraire américain. On ne peut que se réjouir que ce soit à travers la voix sûre, savoureuse, précise, aussi juste que passionnée de Cécile Roudeau. La traductrice a donné à The Country of Pointed Firs toute sa dimension, magnifiant la prose de Jewett dans une langue attentive au plus haut point à sa cadence, à sa substance, à ses harmoniques, avant d'en éclairer éloquemment la complexité dans un commentaire qui tisse ses fils à travers des micro-lectures fines et pénétrantes.

2 Ce commentaire, écrit à l'unisson de la traduction, est tout à la fois une méditation sur l'art de l'écrivain et sur celui de la traductrice, enveloppés dans une mission réciproque : l'une comme l'autre sont préoccupées de créer du lien - lien entre les personnes, entre les hommes et les lieux, entre un pays et un autre, entre l'écriture et la ré-écriture. Restant prudemment à l'écart des orientations plus idéologiques de la critique américaine, Cécile Roudeau articule sa postface autour de cette esthétique du lien, à la fois thème et enjeu formel, propre à faire sens d'un texte souvent tenu pour mineur parce que rebelle aux canons de la "grande littérature»: fictive sans être romanesque, cette œuvre de Jewett joue une partition intimiste, secrète presque. Mais mode mineur, souligne la traductrice, ne signifie pas œuvre mineure. Et de suggérer que l'auteure s'est délibérément exprimée sur ce mode afin d'affirmer et faire entendre une voix autre, en marge du "canon », dont la pertinence apparaît à travers une lecture dont le féminisme mesuré pointe in fine, alors que Jewett apparaît comme représentative des ambitions ou des motivations «d'autres femmes écrivains de son temps ».

3 Peut-être à cet endroit la lecture, certes présentée sur un mode hypothétique, est-elle moins convaincante. La référence à un « centre, institutionnel, politique ou national ", 
par rapport auquel Jewett - au même titre que ses consœurs - aurait tenté de "se libérer ", à "une forme trop établie " dont elle aurait voulu s'affranchir, laisse perplexe. On peine à imaginer ce qu'est précisément ce centre, et ne pourrait-on avancer que tous les écrivains de quelque stature, qu'ils soient hommes ou femmes, écrivent toujours en partie depuis quelque marge, qu'elle soit sociale, politique, littéraire, ou autre? Aussi, plutôt que de rattacher la pratique esthétique de Jewett - privilégiant ce que Cécile Roudeau appelle joliment le patchwork - à une rébellion proprement féminine vis-à-vis du modèle dominant de l'intrigue (plot), censé incarner un désir tout masculin de régenter, peut-être aurait-il été plus juste d'y voir l'expression d'une défiance à l'égard du romanesque profondément ancrée en NouvelleAngleterre, et dont les Transcendentalistes, Emerson et Thoreau en tête, sont un exemple majeur au XIXe siècle. Loin d'être en soi l'expression d'une marginalité, le refus des sortilèges de la fiction représentait assurément un héritage puritain toujours vivace, et les excellentes analyses sur la sobriété et la beauté de la «littérature de pénurie ", vouée à exalter l'ordinaire, auraient elles aussi pu être rattachées à cette tradition.

4 Cette réserve mise à part, la richesse de cette esthétique du patchwork est remarquablement mise en valeur tout au long de l'étude, qui replace également l'œuvre dans son moment historique et son contexte littéraire, faisant vivre toute une parenté intertextuelle où se distinguent Henry David Thoreau et Willa Cather. Ce n'est d'ailleurs pas le moindre des mérites de cette postface que de faire affleurer ou surgir à l'horizon, par-delà le promontoire du Pays des Sapins pointus, toute une contrée littéraire encore largement méconnue du public français: les autres œuvres de Jewett, bien sûr, mais aussi les récits et esquisses de Harriet Beecher Stowe, tels ceux de The Pearl of Orr's Island (1862), largement éclipsés par l'immense et durable célébrité de La Case de l'Oncle Tom, ou ceux de Mary Wilkins Freeman et Rose Terry Cooke.

\section{INDEX}

Thèmes : Recensions

\section{AUTEUR \\ FRANÇOIS SPECQ}

Université Lumière-Lyon2 